\title{
Aa. Vv., Correspondance et poésie (Actes du colloque de Brest, 16-17 octobre 2009)
}

\section{Ida Merello}

\section{Q OpenEdition}

1 Journals

\section{Edizione digitale}

URL: https://journals.openedition.org/studifrancesi/4772

DOI: $10.4000 /$ studifrancesi.4772

ISSN: 2421-5856

\section{Editore}

Rosenberg \& Sellier

\section{Edizione cartacea}

Data di pubblicazione: 1 avril 2012

Paginazione: 174-175

ISSN: 0039-2944

\section{Notizia bibliografica digitale}

Ida Merello, «Aa. Vv., Correspondance et poésie (Actes du colloque de Brest, 16-17 octobre 2009)», Studi Francesi [Online], 166 (I | LVI) | 2012, online dal 30 novembre 2015, consultato il 19 novembre 2021. URL: http://journals.openedition.org/studifrancesi/4772 ; DOI: https://doi.org/10.4000/studifrancesi. 4772

Questo documento è stato generato automaticamente il 19 novembre 2021.

\section{(c)}

Studi Francesi è distribuita con Licenza Creative Commons Attribuzione - Non commerciale - Non opere derivate 4.0 Internazionale. 


\title{
Aa. Vv., Correspondance et poésie (Actes du colloque de Brest, 16-17 octobre 2009)
}

\author{
Ida Merello
}

\section{NOTIZIA}

AA. VV., Correspondance et poésie, (Actes du colloque de Brest, 16-17 octobre 2009) Rennes, Presses Univ. de Rennes, 2011, pp. 291.

1 Il volume raccoglie diversi interventi che riguardano la rassegna. Tra i saggi che riflettono sulla poetica epistolare troviamo gli interventi di André GUYAUX (Rimbaud poète épistolier, pp. 35-40), Olivier BIVORT, Verlaine populaire? pp. 41-58) e Maurice GASNIER (Rendre justice à la poésie? "Le Tombeau de Louis Ménard", pp. 59-72). André GUYAUX ricorda la consuetudine da parte dei poeti di inviare lettere, spesso accompagnate da versi, a poeti più anziani come richiesta di una sorta di padrinaggio. In questa pratica rientra la lettera di Rimbaud a Banville del 1870; mentre, in quella del 1871 rivolta al medesimo, l'A. scorge ormai una forma di derisione. Per quanto riguarda invece la Lettre du voyant, l'A. mostra come la diversa lunghezza delle due stesure, indirizzate rispettivamente a Izambard e a Demeny, riveli la diversa attenzione portata al professore e all'amico poeta. Sotto la forma della lettera, l'A. smaschera quella del saggio, cui solo qualche tocco conferisce il tono epistolare. Lo stesso tono sembra del resto governare Une saison en enfer, per cui l'autobiografia coinciderebbe con una lunga lettera. Tra l'ottobre 1875 e la lettera di Genova del 1878, conclude l'A., si consuma invece l'addio alla poesia e così alla forma poetico-epistolare.

Olivier BIVORT ricorda il pregiudizio critico per cui Verlaine era ritenuto responsabile di un abbassamento della lingua poetica, per mostrare invece la sua attenzione a un impasto nuovo, non convenzionale, che prendesse in conto tutte le componenti della lingua fino a brusche giustapposizioni e rotture di stile. Se gli scarti dal registro 
parnassiano erano già percepibili in Poèmes saturniens, l'A. fa risalire a Romances sans paroles il processo che si afferma poi in misura massiccia in Parallèlement, cercando nella Correspondance conferme non solo della partecipazione attiva di Verlaine al movimento di democratizzazione della poesia, ma anche della sua anticipazione. La Correspondance infatti, che il poeta cura moltissimo, oltre a mostrare per conto proprio un alto tasso di sperimentazione linguistica, consente di contestualizzare la contemporanea creazione poetica, grazie all'inserto nelle lettere di numerosi versi. Il loro invio ai vari corrispondenti svela meglio sia le connivenze che l'ampiezza di irradiazione, testimoniando il ruolo di precursore di Verlaine.

3 Maurice GASNIER rende invece conto di un'operazione di politica editoriale del $1902 \mathrm{da}$ parte di Edouard Champion figlio dell'editore, che invita scrittori, poeti, artisti, storici, filosofi, linguisti, scienziati e politici a partecipare a un Tombeau in onore di Ménard. Si tratta di un Tombeau costituito da lettere che Edouard ha richieste a personaggi che appartengono tutti alla cultura di destra. In tal modo Louis Ménard, che si oppone al romanticismo reintroducendo il culto dell'antichità classica, sembra diventare l'alfiere della contro rivoluzione letteraria. Così, malgrado la sua adesione alla rivoluzione del 1848 e le sue amicizie con gli ambienti socialisti e le sue relazioni con Marx, che pure vengono citate, il Tombeau tende ad annetterlo alla nuova causa della destra nazionalista.

4 Nella sezione «Confidences» troviamo altri interventi utili alla nostra rassegna. Yann MORTELETTE (La naissance d'une vocation poétique: les lettres inédites de José-Maria de Heredia à sa mère, pp. 187-202), dopo aver ricordato che il 95\% della corrispondenza di Heredia è ancora inedita, e risulta comunque incompleta, mostra l'importanza delle lettere alla madre come guida per la nascita e lo sviluppo dell'opera poetica. Nel presentarle i propri versi, Heredia rivela tutta la sua ammirazione per Leconte de Lisle, riconosciuto come maestro, e intanto inserisce rime e inediti che entreranno poi a far parte di altre composizioni, permettendo così di comprendere l'evoluzione della sua poesia e le modalità della creazione.

5 Jean-Louis MEUNIER (Autobiographie d'une âme: Georges Rodenbach en sa correspondance, pp. 203-218) rivela l'ampiezza della corrispondenza dell'autore, ricca sia per consistenza che per il valore dei corrispondenti, da Mallarmé alla maggior parte dei poeti e dei prosatori dell'epoca. L'A. la accosta per importanza alla recente pubblicazione in volume ad opera di Pierre Maes delle prefazioni e degli articoli in cui Rodenbach manifestava il proprio pensiero teorico. La corrispondenza mette in luce una personalità ricca di contrasti, che mostra il dessous des cartes di temi e immagini dell'opera creativa, e manifesta ammirazioni acritiche (per Victor Hugo) mentre tende al mimetismo stilistico con Mallarmé, Goncourt e Montesquiou.

6 Michael PAKENHAM (Déboires d'éditeurs, pp. 229-236) svela, attraverso la corrispondenza, tre occasioni di attrito tra autori ed editori. Nel primo caso descrive le frizioni dell'editore Richard Lesclide con Manet e Mallarmé per l'edizione illustrata della traduzione di Le Corbeau, fino alla minaccia di processo da parte di Mallarmé. Nel secondo ricorda come Verlaine, Cros e altri poeti, rifiutati da Banville, Coppée e France per la terza edizione del Parnasse contemporain si siano rivolti allo stesso Lesclide per una pubblicazione miscellanea di Dixains réalistes (pubblicati nel 2000 dallo stesso Pakenham) che ha subìto una serie di traversie. Nel terzo mostra un Verlaine «homo duplex» nei confronti dei suoi editori, che tenta di evadere da obblighi sottoscritti in nome di utili migliori. 
7 Joëlle ROBERT (Lettres à une femme poète: Gustave Flaubert, Louise Colet et la poésie, pp. 237-246) esamina la corrispondenza tra i due autori, mettendo in evidenza come la donna di undici anni più anziana si trasformi nell'allieva dell'amante/maestro, che pretende di insegnarle il suo rigore e le sue scelte estetiche. Finiranno per questo con l'irritarsi a vicenda, fino alla rottura della relazione.

8 Philippe BARASCUD (Huysmans et la poésie religieuse, pp. 247-258) mette in luce il fastidio di Huysmans per i versi religiosi dei suoi contemporanei, eccezion fatta di Verlaine, che apprezzava già prima della conversione. L'unico altro che trovi poi grazia ai suoi occhi è Adrien Mithouard, con cui scambia una corrispondenza fitta di giudizi negativi nei confronti del resto della poesia religiosa, dal XVI secolo ai contemporanei. Ma l'elogio dei versi di Mithouard, nota l'A., passa attraverso un apprezzamento estetico delle immagini, che ricordano i quadri di Whistler. In conclusione la corrispondenza conferma come la conversione non abbia mutato l'atteggiamento estetizzante dello scrittore. 